\title{
TEXTO-MONTAGEM E EXPERIMENTAÇÃO EM TORNO DE PAZ, BLANCHOT E BENJAMIN
}

\author{
Maria Lúcia Dal Farra
}

\begin{abstract}
agora estamos a ver as palavras como possibilidades de respiração digestão dilatação movimentação experimentamos a pequena possibilidade de uma inflexão quente "elas estão andando por si próprias!" exclama alguém estão a falar a andar umas com as outras

a falar umas com as outras

estão lançadas por aí fora a piscar o olho a ter inteligência para todos os lados sugerindo obliquamente que se reportam a um novo universo ao qual é possível assistir "ver"

como se vê o que comporta uma certa inflexão de voz é uma espécie de cinema das palavras
\end{abstract}

Herberto Helder

(Antropofagias - 1971)

Vulto que ameaça a existência da poesia e que a incita a reorganizar-se, barreira que se levanta entre a imaginação poética e a imagem do mundo, sinal de progresso e de massificação, a técnica catalisa em si o conceito de modernidade. Provedora de relevos e subterrâneos - as grandes cidades, as multidões, o trabalho assalariado - ela expõe a arte à reprodução, à dessacralização e a arremessa a um incógnito e a uma busca desesperada daquilo que ela não permite entrever.

Cortina de aço bruscamente descida entre passado e presente, presente e futuro, a técnica despoja o "hic et nunc" da obra de arte, sua unicidade e irrepetibilidade, singularidade e perduração, e a lança num espaço aberto inaugurado pela vacuidade, ausência e vanidade. 
Daí a palavra errante, a dispersão, o signo em perpétua rotação da obra de arte moderna. Daí que a imagem mais justa ao poeta moderno seja encontrada no herói: esgrimista, proletário, "apache", trapaceiro ou "flâneur" (1) Um herói predestinado à derrota, "un homme trompé dans son expérience, un moderne" (2), um jogador.

Se o conceito de aura em Benjamin, tal como vem enunciado no seu ensaio de 1936 (3) pode socorrer as explicações em torno das transformações que a técnica providencia sobre a pintura, escultura e arquitetura, ele tem atuação reduzida quando se refere à literatura. Desde a separação das artes e até mesmo antes da invenção da imprensa, fazia parte da natureza literária o ser reproduzida, e a palavra falada e a manuscrita atestam o seu sentido de divulgação e de alcance de um público que depois, quando da palavra impressa, viria a se constituir numa "massa"

Neste caso, a aura, enquanto "a única aparição de uma realidade longínqua por mais próxima que possa estar" (4) ou enquanto vinculação entre a produção e tradição, singularidade e perduração, não pode ser afetada quando se imagina o fenômeno da reprodução literária em termos materiais. No que concernè à literatura, conviria observar, levando às últimas consequiências esse conceito de aura, a transformação pela qual a obra passa com o advento da imprensa, sem dissociá-la da metamorfose que torna o recolhimento - exigido pela obra - uma conduta associal. É o divertimento que o substitui agora como uma variedade de comportamento social. Sob o signo da imprensa, um dado novo se insinua: o das relações entre escritor e público leitor (5)

(1). - BENJAMIN, Walter, "A Modernidade", in Vanguarda e Modernidade. Tempo Brasileiro 26-27, Rio de Janeiro, Tempo Brasileiro, jan-março de 1971, p. 7-39, trad. de Heidrun Krieger Mendes da Silva .

(2). - BENJAMIN, Walter, "Sur quelques thèmes Baudelaririens", in Poésie et Révolution, Paris, Denoel, 1971, essais traduits de l'allemand par Maurice de Gandillac, p. 257.

(3) . - BENJAMIN, Walter, "L'oeuvre d'art a l'ère de sa reproductibilité technique", in Opus Cit., p. 171-210.

(4). - BENJAMIN, Walter, "L'oeuvre d'art à l'ère de sa reproductibilité technique", in Opus Cit., p. 178.

(5) -C. f . BARBOSA, João Alexandre, A Metáfora Crítica, São Paulo, Perspectiva, 1974, p. 43.

"Já em 1939, no ensaio Sobre Alguns Motivos em Baudelaire", Walter Benjamin acertava no alvo com precisão ao observar que 'Baudelaire visava leitores para quem a leitura da poesia lírica apresentava dificuldades' Neste sentido, as relações entre o poeta e sua linguagem são dadas simultaneamente pelo modo através do qual são estabelecidas as suas relações com o público visado" 
Diferenças de espaço, sociedade e mitologia fundam as distâncias entre a palavra falada, a manuscrita e a impressa, mas as dessemelhanças se agudizam quando da passagem daquelas à palavra impressa. Se as obras eram uma forma de espelhação e de comunhão com o mundo, símbolos e diálogos, pontos de intersecção entre o homem e sua realidade exterior, elas obedecem, através das letras impressas, a uma concepção linear da história e a um princlpio de causalidade não mais pelos ouvidos, mas pelos olhos; pede atenção, concentração, apresentando-se como tarefa solitária, silenciosa e surda. De ato público e social a ato privado e à passividade. Nesta complexa transição, a categoria inerente à obra de arte — o recolhimento - torna-se cada vez mais, um ato marginalizado.

Não é, por isso, surpreendente que em 1873, condenando a sociedade, Rimbaud também tenha condenado a poesia. Depois de Unt Saison en Enfer, diz Paz (6), não é mais possível escrever um poema sem uma sensação de vergonha. Assim, esse sentimento se dirige ativamente contra a poesia, na medida em que a recusa desta se converte na forma mais expressiva da sua própria manifestação. $\mathrm{Pu}$ dor revertido em crítica, o poema problematiza a experiência poética. o significado, a linguagem e a sua própria existência.

De fato, diante da técnica que se ergue como uma resistência toldando a imagem do mundo, a imaginação poética só pode se defrontar consigo mesma. Se a técnica não é uma linguagem, mas um repertório de signos, um vocabulário aplicado à transformação da realidade, seus signos são instáveis e de uma dinâmica sempre por alcançar À imitação deles, o poema - a exigência de configurar-se perante a técnica - toma as proporções ativas daquilo que não se funda numa visão de mundo, daquilo que é tão mutável quanto o são os signos técnicos. A existência de um vocabulário universal em perpétua transformação e a crise dos significados decorrem daí: o poema é o espaço onde essas metamorfoses carregadas de iminência têm lugar. Debatendo-se com a técnica, a imaginação poética acaba por aceitar as suas regras, não pela passividade mas pelo sentido de ebulição que elas carregam.

A crescente soberania da linguagem sobre o autor apontada em Mallarmé, em Proust, no Surrealismo, em Beckett, em Genet é o atestado desse embate entre poeta e técnica. De fato, a neutralidade impessoal a que Barthes se referiu no "grau zero da escritura" con-

(6) . - PAZ, Octávio, "Os Signos em Rotação" in Signos em Rotação, São Paulo, Perspectiva, 1972 trad. de Sebastião Uchoa Leite, p. 95-123. 
ceitua de maneira mais específica esse fenômeno; a dispersão e a existência de uma não-literatura indiciam a falta de um suporte estável para o horizonte literário que se desmorona na ausência de imagem do mundo.

Paz observa que Blake podia ver o invisível porque tudo, para ele, escondia uma figura. Sua imaginação tinha por finalidade dar forma simbólica e sensível à energia, enquanto Mallarmé anula o visível porque todo o real é imaginário. Para um, a realidade primordial e arquetípica era o mundo, para outro, é a palavra. Palavra de sentranhada dos mecanismos insondáveis da técnica, palavra que percorre suas gamas de significação com a mesma agitação das máquinas que convidam para o jogo, ela brilha, por um momento, num significado lançado ao infinito: signo sem perduração, sem tradição.

Que resta a um signo ao qual a técnica lhe triturou a aura?

Em 1866, Mallarmé se refere ao projeto de Le Livre supondo que constará de cinco volumes; em 1885 imagina que a obra se constituiria de alguns tomos; em 1897 ele publica Un Coup de Dés.

Em todo o caso, Le Livre teria diversas faces, uma em direção ao Nada, outra à Beleza, à Música, às Letras, todas elas resultantes de um fenômeno único construído de forma arquitetônica e premeditada. O espaço poético e sua estrutura seriam aí perscrutados e fora desse $\mathrm{Li}$ vro só seria possível a escritura de "sonetos nulos" Blanchot assegura que, por fim, Mallarmé escreveu somente "poemas nulos" desde que, por meio da busca do centro do Livro, pôde dar existência poética ao que estava fora dele (7)

As especulações de Mallarmé atestam que ele não estava desatenta para com as relações entre poesia, sociedade e história. Mallarmé tem plena consciência do processo de crise de representação em que a obra literária se encontrava, de maneira que o projeto e execução do Livro estão intimamente ligados a este questionamento total. Observando que as condições de sua época são adversas a uma realização favorável de sua obra, Mallarmé propõe que a obra deve pôr em evidência o próprio conflito, a discordância entre literatura e história. Tratava-se, portanto, de escrever uma obra absoluta em condições absolutas.

(7). - BLANCHOT, Maurice, "A Donde va la literatura?", in El Libro que Vendrá, Caracas, Monte Ávila, 1969, p. 219-281. 
O primeiro empecilho a tal execução surge na categoria da casualidade. Suprimindo a realidade vibratória seria possível excluir-se a realidade elocutória, e o poema se faria por si mesmo: as palavras se refletiriam umas sobre as outras, perdendo sua cor própria, de maneira a se tornarem "as transições de uma única gama" Deste modo, impedindo que as palavras nomeassem objetos reais e sensíveis - $\mathrm{e}$ que, portanto, se tornassem casuais - a poesia minaria a substância concreta das realidades particulares e apagaria o poeta-elocutor, deixando transparecer somente "o conjunto de reações que existem no todo" Sua aspiração à música seria consumada: a poesia se converteria na mobilidade pura, num avanço e desdobramento de relações puras. A iniciativa seria dada às palavras e o poema exporia o trabalho transformador delas.

Por outro lado, o verso tradicional parecia a Mallarmé a única forma de vencer a casualidade "palavra por palavra" E de supor que, quebrando-o, a casualidade se libertaria, e aquilo que a recusa da nomeação tinha obtido a favor da necessidade se desfaria com a diluição do verso tradicional. Entretanto, se é possível promover uma correlação precisa entre a forma do poema e a afirmação que o recorre e o sustenta, a necessidade se estabelece como uma nova contradição.

Deste modo, o espaço poético, fonte e "resultado" da linguagem não é uma coisa: as palavras estão ali para designar a extensão de suas próprias relações. As palavras se espacializam e se disseminam, porque quando designadas, se desdobram e se recolhem e se abrem em profundidades de diferentes níveis, interrelacionadas por meio de uma estrutura que não aparece como pressuposto, mas como consequiência .

Este estado de dispersão e de reagrupamento pronto a se dispersar torna-se possível pela apropriação da página como espaço gráfico. Deste modo, o poema não nega o espaço desconhecido criado pela técnica moderna: neutraliza-o e o dissolve reduzindo esse acaso, a transformação ativa e inevitável dos seus signos, ao infinito (8)

(8). - Indicando que Mallarmé, contra "a ditadura da verticalidade" propõe a horizontalidade da escrita, Walter Benjamin escreve: "Como se vislumbrando, no âmago da cristalina construção de sua escritura certamente tradicional, a vera imagem do vindouro, Mallarmé no Coup de Dés reelaborou pela primeira vez as tensões gráficas do reclame na figuração da escrita (Schriftbild). Posteriormente, os Dadaístas empreenderam a pesquisa da escrita, mas o seu ponto de partida não era a construtividade, e sim, antes, o acurado reagir dos nervos dos literatos. Por isso, a pesquisa dadaísta é muito menos consistente que a de Mallarmé, oriunda do que havia de mais intrínseco no estilo deste poeta. Fica, assim, patente, a atualidade da descoberta, daquilo que Mallarmé, monadicamente, no mais íntimo recesso de seu estúdio, porém em pre-estabelecida harmonia com todos os eventos decisivos do seu tempo na 
Por isso mesmo, a obra não tem presente. Sendo, está feita: ela é enquanto está feita, deixando de ter sido feita e dizendo isso a todo instante, "aqui adiantando, ali rememorando em futuro, em passado, de baixo de uma falsa aparência de presente" $O$ presente não será o tempo expressado por ela, mas o existente por baixo dela; seu presente será irreal, um tempo que sendo é impossível. Nesse sentido, a "essência do Livro é a de regressar, irreal, até seu próprio reconhecimento, mostrando o conflito infinito da sua presença evidente e da sua realidade sempre problemática"

Se Un Coup de Dés não é o Livro que Mallarmé pretendia escrever, ele é, pelo menos, a sua mais intensa manifestação. Ele é também o seu ato heróico, o seu suicídio. "Os obstáculos que a modernidade opõe ao élan produtivo natural do indivíduo encontram-se em desproporção com as forças dele. É compreensível que o indivíduo fraqueje, procurando a sorte. A modernidade deve estar sob o signo do suicídio que sela uma vantagem heróica que nada concede à atitude que lhe é hostil. Este suicídio não é renúncia, mas paixão heróica" (9)

Esse suicídio, essa paixão heróica compreendem, em Mallarmé, o fato de esse poema expressar a nulidade do ato de escrever. Sabendose, por antecipação, vencido pela impossibilidade de segurar nas mãos os signos ativos da técnica, o poema os manipula e ao acaso que eles carregam, expressando as reações entre o espaço e o movimento temporal através de uma forma que transforme sempre essas relações. A duração histórica também afetada pela técnica torna-se, no poema, o jogo das relações de proporção e reciprocidade. $O$ relato, tragado pela desarticulação da duração histórica, é também extirpado do poema: não há mais narração porque não há estabilidade. O poema mostra e representa, de maneira sensível e gráfica, o espaço interior do pensamento e da linguagem, por meio da distância espacial, ritmo das palavras, velocidade, aceleração de suas conexões, concentração, dispersão, reprodução, demonstrando, fortuitamente, o objeto que designa e que se encontra sempre em perpétua combustão. Não se permitindo desaparecer perante o fantasma da técnica, o poema antes o imita. Não pela passividade, mas pela crítica que contém a sua própria negação- e a da técnica - e que faz dela o ponto de partida a igual distância da afirmação e da negação.

economia e na técnica, deu à publicidade. A escrita, que tinha encontrado asilo no livro impresso, para onde carreara o seu destino autônomo, viu-se inexoravelmente lançada à rua, arrastada pelos reclames, submetida à brutal heteronomia do caos econômico." BENJAMIN, Walter, "Revisor de Livros Juramentado (1926)" in Mallarmé (Campos, Haroldo et alii), São Paulo, Perspectiva, 1974, p. 193.

(9) - BENJAMIN, Walter, "A Modernidade", in Opus Cit., p. 15. 
Ora, se o trabalho técnico em relação ao trabalho manual pode ser considerado como jogo, um mecanismo reflexo que a máquina aciona no operário, não seria organicamente necessário que o poema que imita e critica a técnica procurasse pôr em evidência essa mesma natureza?

No seu ensaio de 1939 (10), observando que Baudelaire descobre, na figura do desocupado, o processo do "jeu de hasard", Benjamin salienta que não há antítese mais clara que a existente entre trabalho e acaso. Estão presentes no jogo o elemento de aventura, de sedução do jogador pela "miragem" do sucesso, a vacuidade, o vazio, o fato de não poder terminar, características inerentes à atividade do operário assalariado. O princípio que regula o jogo e também o trabalho assalariado é o mesmo: recomeçar sempre, "ao arranque" no movimento da máquina corresponde o "coup' no 'jeu de hasard" $\mathrm{Na}$ máquina, "cada movimento é tão separado daquele que o precedeu quanto um 'coup de hasard' de um outro 'coup' Assim também, a escravidão do assalariado é, à sua maneira, a equivalente daquela do jogador. Os dois são, tanto um quanto outro, vazios de conteúdo" (11)

Se o trabalhador assalariado, de um lado, e o vagabundo, de outro, são as consequiências mais irremediáveis da instauração dos mecanismos econômicos da técnica, não é surpreendente que Un Coup de Dés, pelas possibilidades da sua intenção de "lance", os alcance. Principalmente se se observa que Baudelaire via na figura do jogador "a forma típicamente moderna desse que foi, outrora, o esgrimista, um personagem heróico entre outros" (12) e mais ainda: que o trabalho poético, para ele, equivalia à esgrima. O poema, enquanto jogo, reflete a "miragem" da decodificação e o leitor, enquanto jogador, emite sempre um "golpe de dados" Por isso mesmo, é provável que a intenção maior do "lance" resida na dicotomia crítica entre trabalho e acaso.

Se no "coup" do "jeu de hasard" e no "arranque" do processo automático do trabalho, não há relação entre o golpe e o precedente (13), Un Coup de Dés nega e afirma essa relação, justamente pelo

(10). - BENJAMIN, Walter, "Sur quelques thèmes Baudelairiens", in Opus Cit., p. 225-275.

(11). - BENJAMIN, Walter, "Sur quelques thèmes Baudelairiens", in Opus Cit., p. 254.

(12) - BENJAMIN, Walter, "Sur quelques thèmes Baudelairiens", in Opus Cit., p. 255.

(13). - "L'idée régulatrice du jeu (comme celle du travail salarié) est l'éternel recommencement à partir de zéro)." p. 257 
seu caráter de Constelação que se apoia num "talvez de exceção" Assim, ligando e desligando os signos que ora se transparecem como um sinal, ora como uma "miragem", o poema pede uma penetração intensa de sua linguagem - o exame de um passado meritório que fundamenta o trabalho - e o abandono dessa perscrutação - dada pelo princípio do jogo e do acaso. Mas é o processo de simultaneidade entre jogo e trabalho aquele em que ele se alicerça: de negação e concomitante afirmação.

Nesse sentido, o conceito de língua para Mallarmé, como "um sistema de relações infinitamente complexas cuja originalidade não nos permite recobrar o espaço geométrico ordinário nem o da vida de subordinação", está virtualmente em Un Coup de Dés. O poema desencadeia um processo de semiose que se torna ilimitada, graças ao fato de que cada leitura emite sempre um "golpe de dados" Faz parte, portanto, da sua intenção e natureza, jogar os dados da técnica: permitir que o leitor se convide ao mesmo tempo para o trabalho e para o lazer. Daí que a dicotomia entre recolhimento e diversão, tão caras à existência ou não da aura, se harmonizem nesse questionamento.

Deste modo, quando Benjamin relaciona a aura à "mémoire involuntaire" de Proust, à "mémoire pure" bergsoniana e às "correspondences" baudelairianas, ele permite a possibilidade de se entrever $o$ mesmo fenômeno em Un Coup de Dés.

Diz Benjamin: "a experiência da aura repousa, portanto, sobre a transferência, no nível das relações entre o inanimado - ou a natureza - e o homem, de uma forma de reação corrente na sociedade humana. Desde que somos - ou que acreditamos ser - olhados, levantamos os olhos. Sentir a aura del uma coisa é lhe conferir o poder de levantar os olhos. Os achados da 'mémoire involuntaire' correspondem a um tal poder (elas não se produzem, aliás, senão uma vez; desde que pretendem assimilar uina lembrança, ela escapa imediatamente; assim, elas confirmam uma concepção da aura que vê' nela 'a única aparição de uma realidade longínqua' $\mathrm{O}$ longínquo, por essência, é inaproximável; para a imagem que serve ao culto é, com efeito, capital que não se possa aproximá-la)" (14)

O processo de "transposição" ou de "destruição criadora" utilizado em Un Coup de Dés permite que em cada palavra o passado da sua tradição seja acionado, tal como se ela pudesse reviver toda a sua diacronia, para abandoná-la e retomá-la indefinidamente, tornan-

(14). - BENJAMIN, Walter, "Sur quelques thèmes Baudelairiens", in Opus Cit., p. 268-9. 
do possíveis diferentes contatos entre os interpretantes, de maneira a providenciar infinitas combinaçōes e leituras: lances de dados. Ora, tal processo tende a recuperar o caráter cultural dos signos e a resguardá-los na sua tradição: num momento em que o poeta perde a sua imagem, resta à linguagem a sua aparição.

Mas o caráter abrupto de instabilidade da palavra que se distende, se dissemina e se recolhe, tal como os signos da técnica, torna esse flagrante do significado sempre "iminente" e inacessível.

Irônica resolução. A natureza irrepetível da aura e sua inacessibilidade são dadas em Mallarmé justamente pela imitação dialética da técnica: a causa fundamental da dessacralização da obra de arte. 